\title{
EFFECTS OF HYPOTHALAMIC DEAFFERENTATION ON CRITERIA OF PROLACTIN SECRETION DURING PREGNANCY AND LACTATION IN THE RAT
}

\author{
M. E. VELASCO,* A. CASTRO-VAZQUEZ $\dagger$ AND I. ROTHCHILD $\ddagger$
}

Instituto de Investigaciónes Medicas, Mercedes y Martin Ferreyra, Córdoba, Argentina, and $\ddagger$ Department of Reproductive Biology, Case Western Reserve University School of Medicine, Cleveland, Ohio 44106, U.S.A.

(Received 8th April 1974)

Summary. Frontal hypothalamic deafferentation (FHD), a cut made at a caudal border of the optic chiasma, on Day 1 of pregnancy prevented implantation in most rats, and on Day 7 induced abortion in all rats. Both effects were prevented by progesterone or prolactin treatment and suckling prevented abortion. This cut on Day 14 did not interrupt pregnancy or prevent lactation in response to suckling. Medial hypothalamic deafferentation (MHD), a cut $1.3 \mathrm{~mm}$ caudal to the site of FHD, on Day 1 did not affect pregnancy or maternal behaviour, but caused diabetes insipidus and failure of lactation. After preoptic roof section (cutting of dorsal afferents to the preoptic area) on Day 1, pregnancy continued beyond term, parturition was normal but maternal behaviour was disrupted. Sham deafferentation had no effect on any aspect of pregnancy, parturition, or lactation. A massive arcuate area lesion on Day 1 prevented implantation. The main site of production of PIF may thus lie in the anterior hypothalamus within the boundaries of the FHD and MHD cuts. The preoptic area may suppress PIF secretion during pregnancy or pseudopregnancy; during lactation, other neural inhibitory afferents to the site of PIF production may be activated by the suckling stimulus.

\section{INTRODUCTION}

The regulation of prolactin secretion differs from that of other pituitary hormones in that it is achieved primarily by hypothalamic inhibition of the pituitary's intrinsic capacity to secrete prolactin (Rothchild, 1965; Meites \& Clemens, 1972), although some evidence suggests that a system which further increases this capacity may also exist (Nicoll, Fiorindo, McKennee \& Parsons, 1970). Many apparently unrelated agents can also induce prolactin secretion (Rothchild, 1965). The prolactin inhibiting factor (PIF) seems to be produced in the hypothalamus (Meites \& Clemens, 1972), but neither the site of its production nor the neural pathways controlling it have been exactly defined. This

\footnotetext{
* Present address: Department of Pathology, Case Western Reserve University School of Medicine, Cleveland, Ohio, 44106, U.S.A.

† Present address: Department of Physiology, University of Texas, Southwestern Medical School, Dallas, Texas 75235, U.S.A.
} 
study deals with an attempt to answer some of these questions. It was prompted by the fact that signs of decreased prolactin secretion follow sectioning of the neural connections between the preoptic area and the anterior hypothalamus in rats (Carrer \& Taleisnik, 1970), and the adventitious finding that a semilunar cut about $1 \mathrm{~mm}$ caudal to this site apparently permitted prolactin secretion to continue.

\section{MATERIALS AND METHODS}

General. Female rats of Holtzman origin (body weight 160 to $220 \mathrm{~g}$ ) were maintained at $22^{\circ} \mathrm{C}$ under a light:dark schedule of $14: 10 \mathrm{hr}$ (lights on at 06.00 hours), with free access to food and water. Vaginal smears were recorded daily throughout each experiment. All the experiments were carried out on primigravid, lactating, or lactating pregnant rats. Day 1 of pregnancy was the day of insemination. Except where otherwise indicated, pregnancy was confirmed by observation of implantation sites at laparotomy. Lactating pregnant rats were obtained as described in the 'Results'. Litters were maintained at six young for all lactating rats, and were weighed at frequent intervals during the course of lactation. Maternal behaviour was studied and included nest building, ingestion of the placentae, and cleaning, retrieval and nestling of the young under the mother's abdomen.

Surgical operations. All operations were carried out under ether anaesthesia and a clean but not aseptic technique was used. Frontal (FHD) or medial (MHD) hypothalamic deafferentation was performed with a bayonet-shaped knife similar to that of Halasz \& Pupp (1965); the horizontal blade was $1.5 \mathrm{~mm}$ and the vertical one was $2.0 \mathrm{~mm}$ long. The knife was introdüced in the mid-line to the base of the skull, turned $45^{\circ}$ to right and left and removed in the sagittal plane. Unless otherwise indicated, the animals were positioned in a stereotaxic apparatus with the head angle described by the atlas of de Groot (1959) (upper incisor bar set at $5.0 \mathrm{~mm}$ above the inter-auricular horizontal plane). For FHD, the optimal antero-posterior coordinate, chosen to place the tip of the knife at the posterior portion of the optic chiasma, was found to be $7.8 \mathrm{~mm}$ anterior to the interauricular line (Text-fig. 1, A and C). For MHD, the rat's nose was tilted downward so that the upper incisor bar was $2.5 \mathrm{~mm}$ below the interauricular horizontal plane; the optimal antero-posterior coordinate was $6.5 \mathrm{~mm}$ anterior to the interauricular line (Text-fig. 1, B and C).

For preoptic roof section (PRS), the dorsal afferents to the preoptic area were interrupted by a circular cut in the horizontal plane with a doublebarrelled knife (Velasco \& Rothchild, 1973). The L-shaped knife had a horizontal blade $2.0 \mathrm{~mm}$ long that was placed $5.0 \mathrm{~mm}$ above the horizontal interauricular plane. The antero-posterior coordinate for the shaft of the knife was $7.5 \mathrm{~mm}$ anterior to the interauricular line (Text-fig. 1, D).

For 'arcuate' nucleus lesions, a cathodic DC of $2 \mathrm{~mA}$ for $10 \mathrm{sec}$ was passed through a nichrome wire electrode $0.6 \mathrm{~mm}$ in diameter which was insulated except at its flattened tip. Two foci of coagulation, at antero-posterior coordinates of 4.8 and $5.8 \mathrm{~mm}$, were made on each side, $0.6 \mathrm{~mm}$ from the mid-line and $0.5 \mathrm{~mm}$ from the base of the skull (Text-fig. 1, E). 

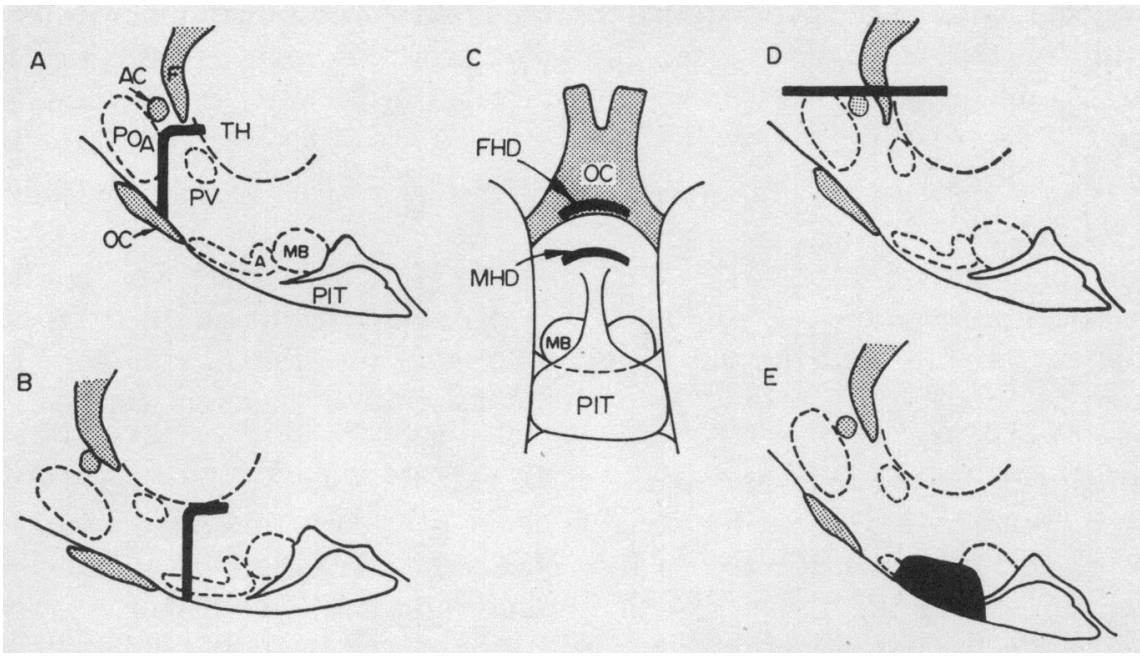

Text-FIG. 1. Diagrammatic representation of sites of hypothalamic deafferentation. A, B, D, E, mid-sagittal section, cephalad on left; $\mathrm{C}$ : ventral view, cephalad above. Cuts or lesion represented in solid black. A, frontal hypothalamic deafferentation (FHD); B, medial hypothalamic deafferentation (MHD); note that in making this cut, the mid-sagittal axis of the base of the skull has been rotated slightly counter-clockwise; C, FHD and MHD viewed from the ventral surface; D, preoptic roof section (PRS); E, arcuate area lesion. $\mathrm{AC}=$ anterior commisure; $\mathrm{A}=$ arcuate nucleus; $\mathrm{F}=$ fornix; $\mathrm{MB}=\mathrm{mam}-$ millary bodies $; \mathrm{OC}=$ optic chiasma $; \mathrm{PIT}=$ pituitary; $\mathrm{POA}=$ preoptic area $; \mathrm{PV}=$ paraventricular nucleus; $\mathrm{TH}=$ thalamus.

Sham operations consisted of lowering the bayonet-shaped knife to the base of the skull in the same coordinates used for FHD but withdrawing it without rotation inside the brain. After operation, each rat was caged individually until the end of the experiment.

Organ weights and water intake. At autopsy, the ovaries, uterine horns, pituitary, and adrenals were weighed and fixed in $10 \%$ formalin. After at least 3 days fixation, the ovaries were again weighed; the percentage difference from the fresh weight was used to estimate the fresh weight of the CL which were dissected from each ovary under a layer of saline with the aid of a dissecting binocular microscope and weighed as a set. The results were expressed as the mean CL weight/rat.

Water intake was determined by means of a graduated water bottle in each rat's cage, and was expressed as the mean water intake/rat/day.

Hormone treatment. Where indicated, oestradiol benzoate, $0.15 \mu \mathrm{g}$ in $0.2 \mathrm{ml}$ of sesame oil, was injected subcutaneously. Progesterone was dissolved in sesame oil at a concentration of $10 \mathrm{mg} / \mathrm{ml}$ and was given subcutaneously at a dose of $2.0 \mathrm{mg} /$ day. Prolactin (NIH-P-S8) was dissolved at a concentration of 12.5 i.u./ml saline and was injected subcutaneously twice a day, each injection consisting of $2.5 \mathrm{i} . \mathrm{u}$. The duration of treatment is indicated in the 'Results'.

Histological confirmation of the site of the cut or lesion. The brains were fixed in $10 \%$ formalin and the location of the cut or lesion was determined by microscopic examination of unstained frozen sections cut serially at $40 \mu \mathrm{m}$ thickness, in the sagittal plane. The findings with only those rats in which the location of 
the cut or lesion corresponded exactly to its designation were included in the 'Results'.

\section{RESULTS}

The effect of hypothalamic deafferentation on Day 1 of pregnancy on implantation and associated changes

The primigravid rats were killed on Day 7 . There were no significant differences between the untreated intact controls and the rats subjected to sham deafferentation or PRS in the incidence of implantation (Table 1), in CL (Table 1), body, uterus, ovary, adrenal, and pituitary weight, or in water intake (Table 2).

The incidence of implantation and the size of the CL (Table 1) were drastically reduced by FHD, but the weights of the other organs, water intake, and body weight were not affected (Table 2). Of the forty-three rats subjected to FHD, ten (including the five with implantation sites) were still in vaginal dioestrus on the day of autopsy; the others remained in dioestrus for 2 (seven rats), 3 (fifteen rats), 4 (ten rats) or 5 (one rat) days before showing pro-oestrous or oestrous vaginal smears. Daily treatment with progesterone from Day 2 to Day 6, or with prolactin from Day 1 to Day 6, permitted implantation and prevented regression of the CL (Table 1).

Implantation was not prevented by MHD (Table 1), and the size and hyperaemia of the CL as well as water consumption were significantly increased (Table 2). The 'arcuate' lesion prevented implantation without affecting CL size (Table 1); water intake was somewhat increased and pituitary, ovary, and adrenal weights were decreased (Table 2).

Table 1. Effect of hypothalamic deafferentation on Day 1 of pregnancy on blastocyst implantation and corpus luteum weight in rats

\begin{tabular}{|c|c|c|c|c|}
\hline Group & Procedure* & $\begin{array}{l}\text { Rats with i } \\
\text { No. of rat }\end{array}$ & $\begin{array}{l}\text { ation sites } \dagger \\
\%\end{array}$ & $\begin{array}{c}\text { Corpus luteum weight } \ddagger \\
(m g)\end{array}$ \\
\hline $\begin{array}{l}1 \\
2 \\
3 \\
4 \\
5 \\
6 \\
7 \\
8\end{array}$ & $\begin{array}{l}\text { Intact } \\
\text { Sham } \\
\text { PRS } \\
\text { FHD } \\
\text { FHD+P } \\
\text { FHD+ PRLN } \\
\text { MHD } \\
\text { ARG }\end{array}$ & $\begin{array}{c}18 / 19 \\
23 / 28 \\
11 / 14 \\
5 / 43 \\
23 / 27 \\
9 / 9 \\
14 / 14 \\
0 / 7\end{array}$ & $\begin{array}{c}95 \\
82 \\
79 \\
11 \cdot 6 \\
85 \\
100 \\
100 \\
0\end{array}$ & $\begin{array}{l}1.80 \pm 0.07 \quad(12) \\
1.90 \pm 0.05 \quad(17) \\
1.67 \pm 0.01 \\
1.09 \pm 0.08 \\
1.81 \pm 0.15 \\
1.84 \pm 0.06 \quad(6) \\
2.29 \pm 0.06^{\mathrm{a}} \quad(12) \\
1.78 \pm 0.06\end{array}$ \\
\hline
\end{tabular}

Day 1 = day of insemination; all rats were killed on Day 7 .

* Sham, knife lowered to base of skull, but not rotated; PRS, preoptic roof section, cutting dorsal afferents to preoptic area; FHD, frontal hypothalamic deafferentation, at level of posterior border of optic chiasma; $P$, progesterone $2.0 \mathrm{mg} /$ day from Day 2 to Day 6; PRLN, ovine prolactin (NIH-P-S8) 5.0 i.u./day from Day 1 to Day 6; MHD, medial hypothalamic deafferentation, cut made $1.3 \mathrm{~mm}$ caudal to FHD; ARC, electrolytic lesion area of arcuate nucleus (see also Text-fig. 1).

$\dagger$ Number of rats with implantation sites (I.S.)/number of rats treated.

$\ddagger$ Mean \pm S.E.M.; number of rats in parentheses. Values noted by ' $a$ ' indicate $P<0.001$ for difference from Intact or Sham controls. In each group, except for Group 4 , the mean CL weight of rats with I.S. was not significantly different from that of the rats without I.S. In Group 4, the five rats with I.S. had a mean \pm S.E.M. CL weight of $1.92 \pm 0.08 \mathrm{mg}$; this was significantly higher $(P<0.01)$ than the weight of the $C L$ of the eighteen rats without I.S. whose CL were weighed. 


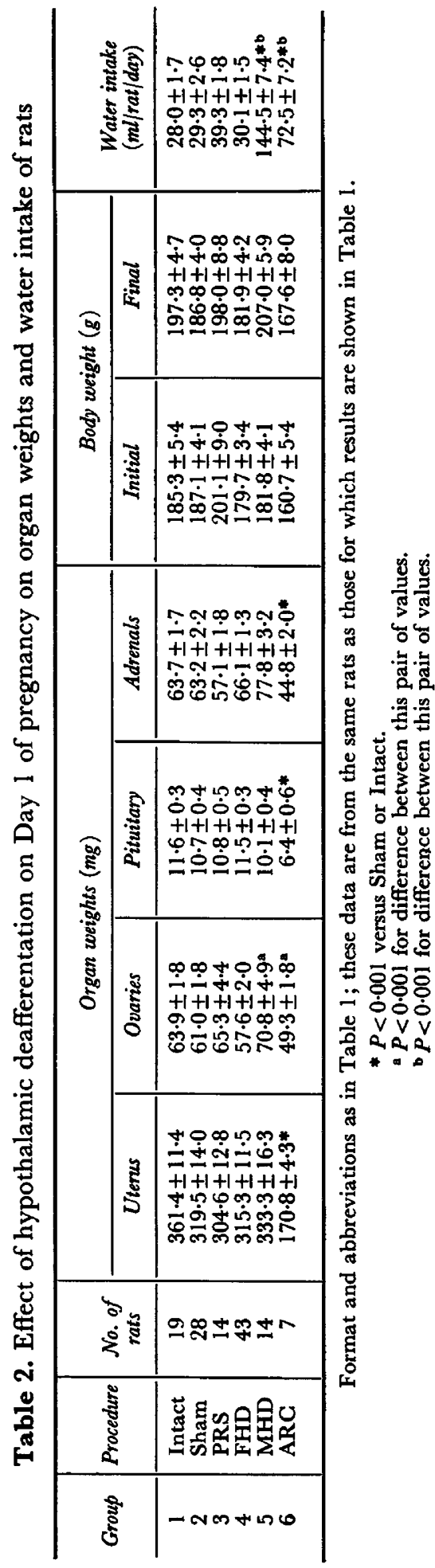




\section{Effect of FHD on Day 7 on the maintenance of pregnancy to Day 14}

On Day 7, normal implantation sites were confirmed by laparotomy in seventeen rats, nine of which were then subjected to FHD and eight to sham deafferentation; all were killed on Day 14. Vaginal bleeding occurred on the 2nd (eight rats) or 3rd (one rat) day after FHD; the interruption of pregnancy in each rat was confirmed at autopsy on Day 14. The intervals to the first pro-oestrous or oestrous vaginal smear were 1 (five rats), 3 (one rat), 4 (two rats) or 7 (one rat) days. Daily treatment with progesterone (three rats) or with prolactin (five rats) from Day 7 to Day 13 permitted pregnancy to proceed normally to Day 14 in an additional group of rats subjected to FHD on Day 7. In the eight rats subjected to sham deafferentation pregnancy progressed normally. The CL of the rats subjected to FHD had a mean ( \pm S.E.M.) weight of $1.37 \pm$ $0.06 \mathrm{mg}$, while those of the controls weighed $3.36 \pm 0.08 \mathrm{mg}$. Through a mishap, those of the progesterone- or prolactin-treated rats were not weighed.

Effect of hypothalamic deafferentation on the duration of pregnancy, parturition, maternal behaviour, and lactation

When FHD was performed on Day 14, it did not interrupt or prolong pregnancy, interfere with normal maternal behaviour, or prevent lactation (Table 3; Text-fig. 2). The performance of MHD on Day 1 was also associated with the maintenance of pregnancy to term, normal parturition and maternal behaviour, but not with lactation (Table 3). When PRS was performed on Day 1, pregnancy was prolonged without affecting fetal survival or the efficiency of parturition, but maternal behaviour was disrupted (Table 3). Sham deafferentation on Day 1 had no effect on any of these aspects of pregnancy or lactation (Table 3). Constant vaginal oestrus occurred in the rats of the FHD group when their young were weaned, and constant vaginal dioestrus in the rats of the MHD group occurred after death of their young. In the PRS and sham-deafferentation

Table 3. Effect of hypothalamic deafferentation on parturition, maternal behaviour and lactation in rats

\begin{tabular}{c|c|c|c|c|c}
\hline Procedure & $\begin{array}{c}\text { Day of } \\
\text { delivery }\end{array}$ & Dystocia* & $\begin{array}{c}\text { Maternal } \\
\text { behaviour } \dagger\end{array}$ & Lactation $\ddagger$ & $\begin{array}{l}\text { Vaginal } \\
\text { smear } \$\end{array}$ \\
\cline { 1 - 5 } Sham (6) & 23 & $0 / 6$ & $6 / 6$ & $6 / 6$ & Cyclic \\
FHD (13) & 23 & $1 / 13$ & $10 / 12$ & $8 / 10$ & COE \\
MHD (7) & 23 & $1 / 7$ & $6 / 6$ & $0 / 6$ & CD \\
PRS (5) & $24,25,26$, & $0 / 5$ & $0 / 5$ & - & Cyclic \\
& 26,29 & & & & \\
\hline
\end{tabular}

Abbreviations as in Table 1. FHD was performed on Day 14 of pregnancy. MHD, PRS and Sham operations were performed on Day 1. The number of rats is shown in parentheses.

* Incomplete or abnormal parturition; e.g. fetuses found dead in vagina.

† Maternal behaviour included nest building, eating placentae and cleaning young, retrieval of young and nestling under the mother's abdomen. Mothers showed either all or none of these aspects of maternal behaviour.

¥ Indicated by milk spots in young and maintenance of the litter to weaning. All litters were weighed approximately every other day throughout lactation except for three of eight litters of the rat's subjected to FHD (see Text-fig. 2).

Following the weaning or death of a litter. COE, constant vaginal oestrus; CD, constant vaginal dioestrus. 


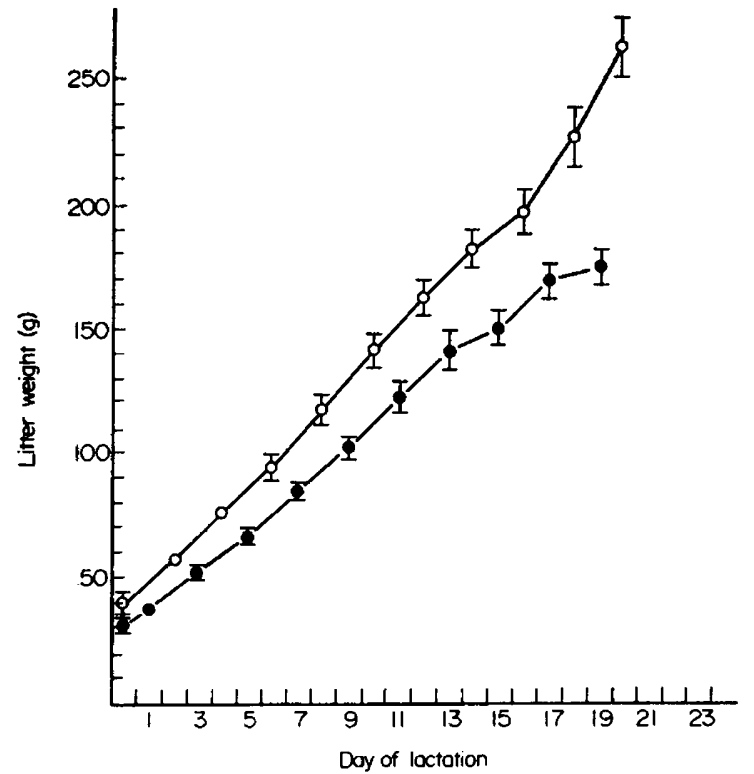

TExT-FIG. 2. Effect of FHD on weight gain of rat litters during the first 20 days after parturition. $O$, Litters of mothers which were subjected to sham deafferentation on Day 1 of pregnancy; 9 , litters of five mothers which were subjected to FHD on Day 14 of pregnancy. Each litter consisted of six young. The entire litter was weighed approximately every other day; weight/litter is shown as the mean \pm S.E.M. Eight rats of the FHD group reared their litters to weaning, though weights were recorded for only five of these litters.

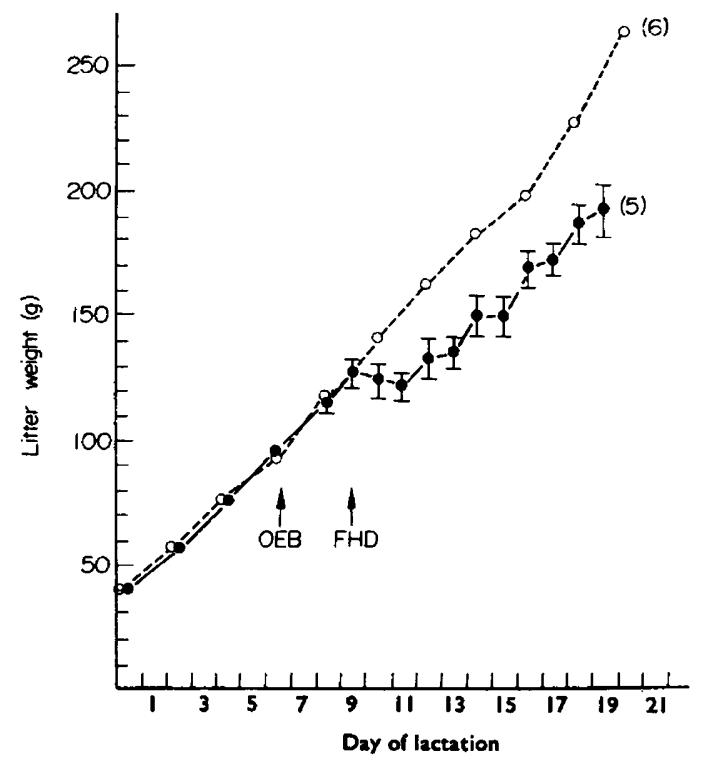

TEXT-FIG. 3. Effect of FHD on the weight gain of litters of pregnant lactating rats. Each litter consisted of six young. $O$, Litters of mothers which were subjected to sham deafferentation on Day 1 of pregnancy (the same rats as in Text-fig. 2); $\bullet$, litters of five lactating pregnant mothers; the mothers were mated on the day of parturition (Day 0 ), injected with $0.15 \mu \mathrm{g}$ oestradiol (OEB) on Day 6, and subjected to FHD on Day 9. All remained pregnant and delivered the second litter on Day 25. Other details as in Textfig. 2. 
groups, oestrous cycles reappeared after death of the litters or weaning, respectively (Table 3 ).

\section{Effect of lactation in pregnant rats on the maintenance of pregnancy after FHD}

On the evening of the day of parturition, normal primiparous pregnant rats were removed from their litters and caged overnight with males, after which those that were inseminated were again allowed to nurse their young. Each was given $0.15 \mu \mathrm{g}$ oestradiol on Day 6 to induce implantation. On Day 9 (assumed to be equivalent to Day 7 in non-lactating pregnant rats), the rats were subjected to FHD. All retained their young, continued to lactate (Text-fig. 3), and gave birth to their second litter on Day 25, an interval after the day of presumed implantation equivalent to Day 23 in non-lactating pregnant rats. The young of the rats subjected to FHD gained little or no weight for 2 to 3 days after the operation, but thereafter they grew at a rate equivalent to that of the control group (Text-fig. 2).

\section{DISCUSSION}

The failure of implantation after FHD on Day 1, and the interruption of pregnancy after FHD on Day 7, are most logically explained as the result of a failure of prolactin secretion, caused by the separation of the anterior hypothalamus from the preoptic area. The rapid appearance of vaginal cornification after FHD showed that the failure of implantation could not have been due to a lack of oestrogen; this cut, in fact, typically induces 'constant oestrus' (Halasz \& Gorski, 1967, and see Table 3). Furthermore, treatment with either prolactin or progesterone allowed implantation to take place and pregnancy to continue. The induction of pseudopregnancy in rats in response to cervical stimulation (Arai, 1969; Carrer \& Taleisnik, 1970), reserpine or progesterone treatment (Carrer \& Taleisnik, 1970) was also prevented by FHD, and when done on Day 4, it prevented the maintenance of pseudopregnancy (Carrer \& Taleisnik, 1970). The pro-oestrous 'surge' of prolactin in cyclic rats (Blake, Weiner \& Sawyer, 1972), and the twice-daily surges of prolactin in pseudopregnant ones (Freeman, Smith, Nazian \& Neill, 1974), could be prevented by FHD. Electrical stimulation of the preoptic area of old intact rats in 'constant oestrus' has also been shown to increase the level of prolactin in the circulation (Wuttke \& Meites, 1973).

Elevated levels of circulating prolactin, however, have been found several weeks after FHD of female rats (Blake et al., 1972). Stimulation of the preoptic area in normal intact female rats failed to induce pseudopregnancy (Everett \& Quinn, 1966) and, in fact, caused the circulating prolactin level to fall (Clemens, Shaar, Kleber \& Tandy, 1971). These findings are not necessarily at variance with our interpretation. Oestrogens are known to stimulate prolactin secretion (Meites \& Clemens, 1972; Ajika, Krulich, Fawcett \& McCann, 1972; Neill, 1972; Kalra, Fawcett, Krulich \& McCann, 1973); the oestrogens secreted in association with the chronic effects of FHD could, therefore, have restored prolactin secretion (Blake et al., 1972). In fact, a later report showed that male 
rats had depressed levels of circulating prolactin after FHD (Blake, Scaramuzzi, Norman, Hilliard \& Sawyer, 1973). Wuttke \& Meites (1973) stimulated the preoptic area of their old rats through indwelling electrodes, and so used no anaesthesia, while Everett \& Quinn (1966) and Clemens et al. (1971), used pentobarbital and urethane, respectively, for their acute experiments. These long-acting anaesthetics may have differentially affected the prolactin secretion response to stimulation of the preoptic area. For example, in cyclic rats anaesthetized with ether, electrochemical stimulation of the preoptic area (but not of the caudate nucleus) with a positive DC through stainless steel electrodes consistently induced pseudopregnancy; electrolytic lesions induced by a negative DC in the same area, however, consistently failed to do so (M. E. Velasco, unpublished findings).

The prevention of prolactin secretion is apparently a specific effect of FHD, since sham deafferentation, MHD and PRS prevented neither implantation nor the maintenance of pregnancy. The failure of lactation in the rats subjected to MHD was probably not due to a lack of prolactin, but to a lack of oxytocin, since this cut also interrupted the supraoptic-hypophysial pathway (Text-fig. 1, $\mathrm{B})$, the effect of which was also reflected in the increased water consumption of these rats (Table 2). Lactation failed in the rats subjected to PRS because of the disruption of maternal behaviour, an effect similar to that caused by septal lesions in the rabbit (Cruz \& Beyer, 1972); in the latter, the lesion did not prevent milk accumulation in the mammary glands.

The arcuate area lesion also prevented implantation (Table 1), and a pilot study has indicated that even when made on Day 7 , it is generally incompatible with the maintenance of pregnancy. The lesion, however, is known to induce prolactin secretion (Gale \& McCann, 1961) and to prevent LH and FSH secretion, as do other methods of pituitary denervation (Rothchild, 1965). The normal size of the CL in the rats with arcuate area lesions was consistent with the maintenance of prolactin secretion (Table 2). A lack of oestrogen, therefore, was almost certainly responsible for the failure of implantation in these rats; indeed, oestrogen treatment of such rats will induce implantation (Gale \& McCann, 1961). The interruption of pregnancy when a lesion was made in the arcuate area after implantation can be ascribed to a deficiency of LH (Raj \& Moudgal, 1970), since LH becomes critically necessary for the regulation of progesterone secretion between Days 8 and 11 of pregnancy (Morishige \& Rothchild, 1974).

The maintenance of pregnancy after FHD on Day 14 (Table 3) was consistent with the fact that the pituitary is no longer necessary after Day 12 (Pencharz \& Long, 1933); in fact, prolactin itself can be dispensed with as early as Day 8 without interrupting pregnancy in intact rats (Kisch \& Shelesnyak, 1968; Morishige \& Rothchild, 1974).

Our findings suggest that the principal site of PIF production may lie within a basal hypothalamic area extending $1.0 \mathrm{~mm}$ caudally from a line roughly parallel to the posterior border of the optic chiasma. The maintenance of prolactin secretion, therefore, must involve a continuous suppression of this PIF 'centre'. The preoptic area may be one site of origin of inhibitory afferents to this 'centre' and stimuli such as coitus and oestrogen may activate specific 
preoptic area neurons in a way that induces and maintains the prolactin secretion characteristic of pregnancy or pseudopregnancy. As we have suggested above, oestrogens may also act either by directly suppressing PIF production or by activating inhibitory neurons the connections of which to the PIF 'centre' may be through other routes than this anterior pathway.

The ability of suckling to maintain prolactin secretion in rats with FHD (Table 3; Text-figs 2 and 3), does indicate that there must be other neural inhibitory afferents to the PIF 'centre' in addition to the anterior ones. All of the basal hypothalamus posterior to the frontal cut remains intact after FHD, so any of the connections of the 'centre' to the rest of the hypothalamus as well as between the latter and the remainder of the central nervous system may contain specific inhibitory pathways to the PIF 'centre'. The most obvious of these is the median forebrain bundle.

The reasons for the increased size of the $\mathrm{CL}$ in rats subjected to MHD (Table 1) and for the restoration of CL weight by means of progesterone treatment in rats subjected to FHD (Table I) are not obvious and must await further investigation.

\section{ACKNOWLEDGMENTS}

This study was supported in part by grants from the Consejo Nacional de Investigaciónes Científicas y Técnicas of Argentina, and by Ford Foundation Training Grants 67-135 and 670-0135A. We are grateful to the Hormone Distribution Program of the NIH for the gift of prolactin (NIH-P-S8).

\section{REFERENCES}

AJika, K., Krulich, L., FAwcetr, G. P. \& McGanN, S. M. (1972) Effects of estrogen on plasma and pituitary gonadotropins and prolactin, and on hypothalamic-releasing and inhibiting factors. Neuroendocrinology, 9, 304.

ARAI, Y. (1969) Effect of hypothalamic de-afferentation on induction of pseudopregnancy by vaginalcervical stimulation in the rat. F. Reprod. Fert. 19, 573.

Blake, G. A., Scaramuzzi, R. J., Norman, R. L., Hilliard, J. \& Sawyer, G. H. (1973) Effects of hypothalamic deafferentation on circulating leveis of LH, FSH, prolactin and testosterone in the male rat. Endocrinology, 92, 1419.

Blake, C. A., Weiner, R. I. \& SAwYer, C. H. (1972) Pituitary prolactin secretion in female rats made persistently estrous or diestrous by hypothalamic deafferentation. Endocrinology, 90, 862.

GARRER, H. F. \& TALEISNIK, S. (1970) Induction and maintenance of pseudopregnancy after interruption of preoptic hypothalamic connections. Endocrinology, 86, 231.

Clemens, J. A., ShaAr, G. J., Kleber, S. W. \& Tandy, W. A. (1971) Reciprocal control by the preoptic area of LH and prolactin. Expl Brain Res. 12, 250.

GRUz, M. L. \& BEYER, C. (1972) Effects of septal lesions on maternal behavior and lactation in the rabbit. Physiol. Behav. 9, 361.

de Groot, J. (1959) The Rat Forebrain in Stereotaxic Coordinates. N.V. Noord-Hollandsche Uitgeeves Maatschappij, Amsterdam.

EveretT, J. W. \& QuinN, D. L. (1966) Differential hypothalamic mechanisms inciting ovulation and pseudopregnancy in the rat. Endocrinology, 78, 141.

Freeman, M. E., Smtth, M. S., Nazian, D. J. \& Neill, J. D. (1974) Ovarian and hypothalamic control of the daily surges of prolactin secretion during pseudopregnancy in the rat. Endocrinology, 94, 875.

GALE, C. C. \& MCCANN, S. M. (1961) Hypothalamic control of pituitary gonadotrophins. Impairment in gestation, parturition and milk ejection following hypothalmic lesions. F. Endocr. 22, 107.

HaLAsz, B. \& GoRski, R. A. (1967) Gonadotrophic hormone secretion in female rats after partial or total interruption of neural afferents to the medial basal hypothalamus. Endocrinology, 80, 608. 
HALAsz, B. \& PUPP, L. (1965) Hormonal secretion of the anterior pituitary after physical interruption of all nervous pathways to the hypophysiotrophic area. Endocrinology, 77, 553 .

Kalra, P. S., Fawcett, C. P., Krulich, L. \& McGann, S. M. (1973) The effects of gonadal steroids on plasma gonadotropins and prolactin in the rat. Endocrinology, 92, 1256.

Kisch, E. S. \& ShelesnyaK, M. G. (1968) Studies on the mechanism of nidation. XXXI. Failure of ergocornine to interrupt gestation in the rat in the presence of foetal placenta. $\mathcal{F}$. Reprod. Fert. 15, 401 .

Meites, J. \& Clemens, J. A. (1972) Hypothalamic control of prolactin secretion. Vitams Horm. 30, 165.

MoRishige, W. K. \& RothCHILD, I. (1974) Temporal aspects of the regulation of corpus luteum function by luteinizing hormone, prolactin and placental luteotrophin during the first half of pregnancy in the rat. Endocrinology, 95, 260.

NEILL, J. D. (1972) Sexual differences in the hypothalamic regulation of prolactin secretion. Endocrinology, 92, 1154.

Nicoll, G. S., Fiorindo, R. P., McKennee, G. T. \& Parsons, J. A. (1970) Assay of hypothalamic factors which regulate prolactin secretion. In Hypophysiotrophic Hormones of the Hypothalamus: Assay and Chemistry, p. 115. Ed. J. Meites. Williams \& Wilkins, Baltimore.

Pencharz, R. I. \& Long, J. A. (1933) Hypophysectomy in the pregnant rat. Am. F. Anat. 53, 117.

RaJ, H. G. M. \& Moudgal, N. R. (1970) Hormonal control of gestation in the rat. Endocrinology, 86, 874.

RoтнсніL, I. (1965) Interrelations between progesterone and the ovary, pituitary, and CNS in the control of ovulation and the regulation of progesterone secretion. Vitams Horm. 23, 209.

Velasco, M. E. \& Rothchild, I. (1973) Factors influencing the secretion of luteinizing hormone and ovulation in response to electrochemical stimulation of the preoptic area in rats. F. Endocr. $58,163$.

WUtTKE, W. \& MerTes, J. (1973) Effects of electrochemical stimulation of medial preoptic area on prolactin and luteinizing hormone release in old female rats. Pfügers Arch. ges. Physiol. 341, 1. 